\title{
Sports Anxiety among High School Athletes 中學運動選手的蓮動焦慮
}

\author{
M.S. Omar-FAUZEE LAI Wing Wai SOH Kim Geok \\ Universiti Putra Malaysia, MALAYSIA
}

Rozita ABD LATIF

Universiti Teknologi MARA, MALAYSIA

莫哈末蘇華安 賴詠瑋 蘇金玉

馬來西亞博特拉大學

羅芝姐

馬來西亞瑪拉工藝大學

\begin{abstract}
This study examined competitive anxiety in sports among the participants in a high school located in Kuala Lumpur, Malaysia. One hundred and fifteen students $(60$ males and 55 females $)$ took part in this study, all of who at least participated in a sport or game representing sport house, school, or district level. All subjects were 15 years old. The results showed that there was a significant difference between male and female participants where male participants reported lower level of competitive anxiety than female. As predicted, participants represented district level also reported lower of competitive anxiety compared to participants representing sport house or school level. No significant difference in competitive anxiety emerged among participants of different ethnicity. Recommendations were suggested for further studies.
\end{abstract}

Key words: Competitive anxiety, sports participation, and High school students, Level of representation in sports

摘要
本文旨在探討馬來西亞吉隆坡中學運動選手的競賽運動焦慮情況。邀請了60位男生和55位女生參加是次研究, 結果顯示 : 男
生的競賽焦慮情緒低於女生, 明䭭差異也存在於來自不同地區的學生及學校組別等。

\section{Introduction}

In a sport competition, anxiety is one of the factors that causes a decrease in performances among athletes (Weinberg \& Gould, 2007). Athletes may experience negative affective states, the antecedents of such situations and the possible means that will enable sport performers to cope successfully with their negative emotions (Biddle \& Ntoumanis, 1998). Recent attention has focused on the multidimensional theory of anxiety. Morris, Harris, and Hutchings (1981) have distinguished between cognitive anxiety and somatic anxiety. They referred to negative expectations and cognitive concerns about oneself and the situation as the element of cognitive anxiety, while the somatic component of anxiety reflects perceptions of physiological responses such as nervousness and tension. According to Davidson and Schwartz (1976), cognitive anxiety was characterized by negative concerns 
about performance, inability to concentrate, and disrupted attention, while somatic anxiety was perceived as increase in autonomic arousal with negative physiological effects, like tense muscles, sweating, increased heart rate and shortness of breath.

Investigations, for instance, have indicated that both social and performance evaluation and pre-performance expectancies are highly correlated with increased cognitive anxiety and link to decrements in performance (Morris, Harris, \& Rovins, 1981). Worry, a form of cognitive anxiety has also been shown to consistently relate to decrements in academic performance (Sarason, 1984). Somatic anxiety, however, tends to produce performance impairment only on tasks requiring precision and accuracy. According to Hardy (1990), cognitive anxiety is responsible for mediating the effects of physiological arousal on performance. Previous studies have found that better athletic performance was associated with lower levels of cognitive and somatic anxiety (Rodrigo, Lusiardo, \& Pereira, 1990).

One significant advance in understanding the nature of competitive anxiety was the motion of "direction" of anxiety (Jones, 1991). This refers to how sport performers label the intensity of the cognitive and physiological symptoms they experience on a debilitate-facilitative continuum. According to Jones (1995), anxiety symptoms are perceived as facilitative or debilitate depending on athletes' perceptions of the control they can exert over the environment and the self and on their belief regarding their ability to cope with anxiety they experience to attain their goals. Wine (1980) also suggested that anxiety symptoms may be perceived as positive (facilitative) or negative (debilitate) by different individuals. In some studies, Jones and Swain (1995) supported some predictions of the control model and substantiated the need for distinguishing between intensity and interpretation (direction) of anxiety symptoms.

Sex differences in competition state anxiety have also been explored (Swain \& Jones, 1991). Findings to date suggest that females not only report higher levels of competitive state anxiety prior to competition than males but that they also conform to different temporal patterning of cognitive anxiety and somatic anxiety during the pre-competition period (Jones \& Cale, 1989). For example, Martens, Burton, Vealey, Bump, and Smith (1990) investigated anxiety and confidence in male and female collegiate athletes, high school athletes, and National Sport Festival competitors. Overall, the female athletes and high school athletes displayed higher cognitive and somatic anxiety than the male athletes and National Sport Festival athletes respectively. Krane and Williams (1987) suggested that differences in cognitive and somatic anxiety between high school gymnasts and college golfers may have resulted from the less experienced high school athletes being less capable of controlling negative thoughts than the more experienced college athletes.

The great desire to win and afraid to lose prompted athletes to have jitters before competing. Besides that, pressures from other parties such as coaches, parents, friends and community also play a role in aggravating the situation and thus, increases the level of anxiety. This is because the expectations placed on the athletes are too demanding and if they don't win, shame, guilt and embarrassment are threats to them. It is of great importance to determine what induces athletes to experience anxiety before a competition so that solutions could be carried out to overcome those problems. Some of the suggested solutions are relaxation training, deep breathing, visualization, imagery, mental practice and selftalk.

The objectives of this study were to find out and determine the competitive anxiety level in sports among the high school athletes in one of High School in Kuala Lumpur, Malaysia. An another objective is to determine whether there were significant differences in terms of competitive anxiety on ethnicity, gender and level participation. Through this study, the researcher will get to know the factors that caused anxiety among the high school athletes mentioned. Besides that, with the data obtained, the athletes will of use to the coaches to plan some effective methods to overcome or reduce the competitive anxiety encounter it.

\section{Methods}

\section{Subjects}

Using convenient sampling, a total of 115 students from one of High School in Kuala Lumpur took part in this study. All of the students were aged 15 and studying at form three. Their levels of participation in sport are represented sport house, school, and district. In terms of 
gender, subjects consisted of 60 males (52.2\%) and 55 females $(47.8 \%)$. With respect to ethnicity, the majority of subjects $(n=82,71.3 \%)$ were Malays, while there were 26 Chinese $(22.6 \%)$ and 7 Indian $(6.1 \%)$.

\section{Instrument}

Data were collected quantitatively using the Sport Competition Anxiety Test (SCAT) developed by Martens (1977). Vealey (1990) reported the test-retest reliability, ranged from .82 to .87 whereas Martens, Vealey, and Burton (1990) reported internal consistency, coefficients ranged from .80 to 92. A modified and translated version of the original instrument was used to measure competitive anxiety among the participants with internal consistency of .78 to 84 . This instrument consisted of 14 items based on a three-point Likert scale in which 1 represented hardly ever, 2 represented sometimes and 3 often. Subjects were to respond to items pertaining to demographic information such as age, gender, ethnicity and highest level of participation in sport.

\section{Procedures}

Prior to data collection, researcher has asked the school headmistress's consent to distribute the questionnaires to the Form Three students. The researcher herself distributed the questionnaires to all the Form Three students that had at least represented the sport house in sports or games. The subjects were told to ask for help if confused concerning either instructions or particular item clarity. No problems were encountered in the completing of the questionnaires and responses were kept anonymous.

\section{Result}

Results show that the mean and the standard deviation of competitive anxiety in the study. The mean was 28.98 (sd = 5.58) which shows that the level of competitive anxiety was quite high among the participants.

One-way ANOVA was performed to determine whether there were significant differences in terms of competitive anxiety on ethnicity and level of participation. Results were significantly difference for the three level of participation $\mathrm{F}(2,112)=188.11, \mathrm{p}<.0 .5$. The district Zone $(\mathrm{M}=18.67, \mathrm{SD}=3.06)$ differed significantly from participants represented sport house $(\mathrm{M}=31.39, \mathrm{SD}=$
2.66) and school $(\mathrm{M}=31.13, \mathrm{SD}=2.54)$ in terms of competitive anxiety. The Turkey post hoc test also shows a significance difference between district zone with school and house representation (Table 1).

Table 1. Turkey HSD Post-hoc Comparisons for level of Participants of Competitive Anxiety AmongHigh School Participants.

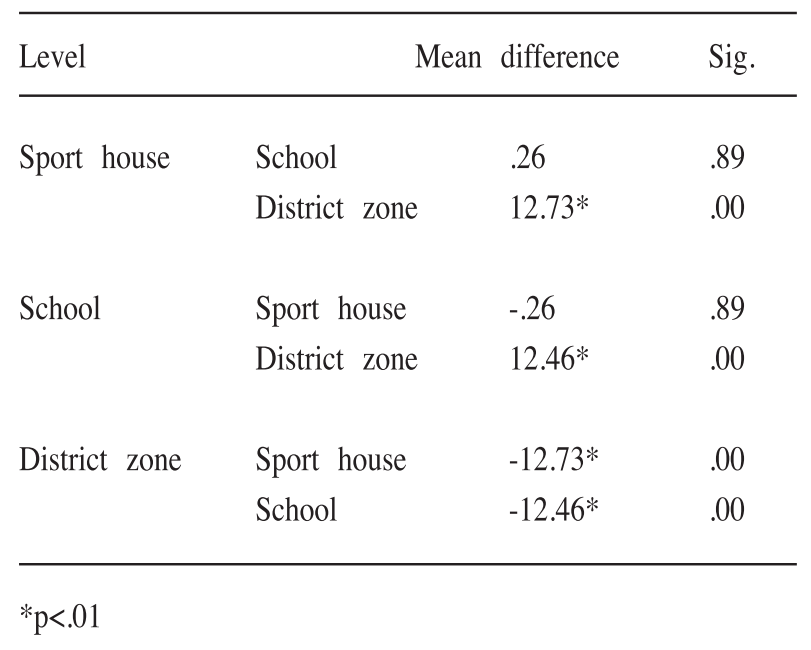

A one way-ANOVA was performed to compare a competitive anxiety among racial groups. Results suggested no significant differences ( $p>.05)$ among these three racial groups. Then t-test was performed to compare whether male and female participants differed in terms of competitive anxiety. Results showed significant difference $t$ $(113)=2.17, \mathrm{p}<.05$. This indicates female participants experienced higher level of competitive anxiety $(\mathrm{M}=$ 27.92, $\mathrm{SD}=5.97$ ).

\section{Discussion and Conclusion}

The purpose of this study was to examine competitive anxiety in conjunction with gender, the level of participation and ethnicity among high school students. Results suggested that female students experienced greater competitive anxiety than male students. Brustad and Weiss's (1987) statement, which mentioned females tending exhibit higher levels of competitive trait anxiety than males, supported this result. According to Jones and Cale's (1989) study, showed no changes in cognitive anxiety during the pre-competition period, while females reported a gradual elevation as the competition neared. This stems from the argument that women were not suited, because of their innate physical and emotional characteristics, to competitive sports (Hargreaves, 1985; 
Dunning, 1986). Thus, when exposed to competition, males may not experience as mush anxiety as females. Also, females are more open and honest in their selfreporting of anxiety and are more forthright concerning their feelings, and thus are more likely to reveal emotions that may perceived as undesirable (Krane \& Williams, 1994).

Athletes who represented district showed less competitive anxiety than athletes who represented sport house or school. Study had indicated that less experienced athletes displayed extremely high levels of cognitive and somatic anxiety (Krane \& Williams, 1994). Athletes representing sport house or school were considered to be less experienced. Thus, the more experienced athletes would display lower level of anxiety than the less experienced athletes were supported. This was consistent with previous studies (Krane \& Williams, 1987). Another explanation, consistent with Heyman's (1982) concerns regarding the relationship of psychological states to performance, may be that experienced athletes had experienced more success and thus came to view competition as less stressful.

However, there was no significant difference of competitive anxiety among high school participants in terms of ethnicity that considered of Malay, Chinese and Indian. The reason being was that, the participants were Form three students, all of whom are sitting for their Penilaian Menengah Rendah (PMR) examination in two months time. According to Arthur (1998), attending classes, taking tests, doing homework and making unrealistic demands on themselves keep students running into busy schedules. This type of lifestyle may directly contribute to high levels of anxiety regardless of ethnicity or socio-economic status (Thompson, Bentz, \& Liptzin, 1973).

Various methods could be used to lessen the level of competitive anxiety among high school athletes. Here are some suggestions, such as relaxation procedures (progressive relaxation, autogenic training, meditation, biofeedback and hypnosis), coping strategies and imagery programs (mental practice) (Cox, 2002). An interesting future research direction is to examine the possible interactions between competitive anxiety and goal orientations or self-confidence among high school participants. This would help to better understand the level of anxiety between different variables.

\section{References}

Arthur, N. (1998). The effects of stress, depression and anxiety on post-secondary students' coping strategies. Journal of College Student Development, 39, 11-22

Biddle, S., \& Ntoumanis, N. (1998). The relationship between competitive anxiety, achievement goals, and motivational climates. Research Quarterly for Exercise and Sport, 69, 176187.

Brustad, R.T., \& Weiss, M.R. (1987). Competence perception and sources of worry in high, medium and low competitive trait-anxious young athletes. Journal of Sport Psychology, 9, 97105.

Cox, R.H. (2002). Sport psychology: Concepts and applications (5 ed.). New York:McGraw-Hill

Davidson, R.J., \& Schwartz, G.E. (1976). The psychobiology of relaxation and related states: A multidimensional process theory. New Jersey: Prentice Hall.

Dunning, E. (1986). Sport as a male preserve: Notes on the social sources of masculine identity and its transformations. Theory, Culture and Society, 3, 79-90.

Hardy, L. (1990). A catastrophe model of performance in sport. In J.G. Jones \& L. Hardy(Eds.), Stress and performance in sport (pp. 81-106). Chichester, England: Wiley.

Hargreaves, J.A. (1985). Playing like gentlemen while behaving like ladies: Contradictory features of the formative years of women's sport. British Journal of Sports History, 8, $40-52$.

Heyman, S.R. (1982). Comparisons of successful and unsuccessful competitors: A reconsideration of methodological questions and date. Journal of Sport Psychology, 4, 295-300. 
Jones, G. (1991). Recent developments and current issues in competitive state anxiety research. The Psychologist, 4, 152-155.

Jones, G. (1995). More than just a game: Research developments and issues in competitive anxiety in sport. British Journal of Psychology, 86, 449-478.

Jones, J.G, \& Cale, A. (1989). Precompetition temporal patterning of anxiety and self-confidence in males and females. Journal of Sport Behavior, 12, 183-195.

Jones, G., \& Swain, A.B.J. (1995). Predispositions to experience debilitative and facilitative anxiety in elite and non-elite performers. The Sport Psychologist, 9, 201-211.

Krane, V., \& Williams, J.M. (1994). Cognitive anxiety, somatic anxiety, and confidence in track and field athletes: The impact of gender, competitive level and task characteristics. International Journal of Sport Psychology, 25, 203-217.

Martens, R. (1977). Sport competition anxiety test. Champaign, IL: Human Kinetics.

Martens, R., Vealey, R.S., \& Burton, D. (1990). Competitive anxiety in sport. Champaign, IL: Human Kinetics.

Martens, R., Burton, D., Verley, R.S., Bump, L.A., \& Smith, D.E (1990). Development and validation of the Competitive State Anxiety Inventory-2. In R. Martens, R.S. Vealey, \& D. Burton (Eds.), Competitive anxiety in sport (pp. 119-190). Champaign, IL: Human Kinetics.

Morris, L.W., Harris, E. W., \& Hutchings, C.H. (1981). Cognitive and emotional components of anxiety: Literature review and a revised worry-emotional scale. Journal of Education Psychology, 73, 541-555.

Morris, L.W., Harris, E. W., \& Rovins, D.S. (1981). Interactive effects of generalized and situational expectancies on cognitive and emotional components of social anxiety. Journal of Research in Personality, 15, 302-311.
Rodrigo, G., Lusiardo, M. \& Pereira, G. (1990). Relationship between anxiety and performance in soccer players. International Journal of Sport Psychology, 21, 112-120.

Sarason, I.G. (1984). Stress, anxiety, and cognitive interference: Reactions to tests. Journal of Personality and Social Psychology, 46, 929-938.

Swain, A., \& Jones, G. (1991). Gender role endorsement and competitive anxiety. International Journal of Sport Psychology, 22, 50-65.

Thompson, J.R., Bentz, W.K., Liptzin, M.B. (1973). The prevalence of psychiatric disorder in an undergraduate population. The Journal of American College Health Association, 21, 415-422.

Vealey, R.S. (1990). Advancements in competitive anxiety research: Use of the Sport Competition Anxiety Test and Competitive State Anxiety Inventory-2. Anxiety Research, 2, 243-261.

Weinberg, R.S., \& Gould, D. (2007). Foundations of sport and exercise psychology (4 $4^{\text {th }}$. ed.). Champaign, IL: Human Kinetics.

Wine, J.D. (1980). Cognitive-attentional theory of test anxiety. In I.G. Sarason (Ed.), Test anxiety: Theory, research and applications (pp. 327-348). Hillsdale, NJ: Erlbaum.

\section{Correspondence:}

Dr. SOH Kim Geok

Sports Studies Department,

Faculty of Educational Studies,

University Putra Malaysia, MALAYSIA

E-mail: kim@educ.upm.edu.my or kimgeoks@yahoo.com Tel: 603-89468153 (Office) or 6019-3649715 (Mobile) Fax:603-89435386 